Quim. Nova, Vol. 36, No. 6, 914-920, 2013

\title{
SUSTENTABILIDADE AMBIENTAL: UM ESTUDO COM PESQUISADORES QUÍMICOS NO BRASIL
}

\author{
Carlos Alberto Marques* \\ Departamento de Metodologia de Ensino da Universidade Federal de Santa Catarina, CP 476, 88040-970 Florianópolis-SC, \\ Brasil \\ Fábio Peres Gonçalves e Santiago Francisco Yunes \\ Departamento de Química da Universidade Federal de Santa Catarina, CP 476, 88040-970 Florianópolis-SC, Brasil \\ Adélio A. S. C. Machado \\ Departamento de Química, Faculdade de Ciências da Universidade do Porto, R. do Campo Alegre, 687, Porto 4169-007, Portugal
}

Recebido em 22/11/12; aceito em 2/4/13; publicado na web em 6/5/13

\begin{abstract}
ENVIRONMENTAL SUSTAINABILITY: A STUDY INVOLVING CHEMICAL RESEARCHERS IN BRAZIL. A study evaluating Brazilian chemical researchers understanding of the scope of the terms Environmental Sustainability and Sustainable Development, and their assessment of how to deal with environmental fragility and limits, is reported. Results showed a certain degree of acknowledgement of the need for a more sustainable development, but little agreement on the magnitude of the environmental limits. The researchers recognized the limitations of the classical paradigms "of dilution" and "of risk", but showed no agreement on the requirements of the new "ecological paradigm" based on Environmental Sustainability and the 12 principles of Green Chemistry, important to assess the role of Green Chemistry for Sustainability.
\end{abstract}

Keywords: environmental sustainability; green chemistry; thermodynamics.

\section{INTRODUÇÃO}

Educar para um modo de vida sustentável considerando os limites físicos do ambiente tem se tornado uma preocupação social e uma "exigência" para se alcançar a salvaguarda do planeta. Isto se deve ao reconhecimento internacional de inúmeros e preocupantes - e às vezes controversos — problemas contemporâneos, como: as mudanças climáticas, a escassez e má distribuição dos suprimentos alimentares, as grandes migrações derivadas da fome e desastres ambientais; o esgotamento de bens naturais e fontes energéticas carbonosas; a escassez de água potável; a geração e despejo de substâncias tóxicas no ambiente e as responsabilidades pela poluição. Enfrentar tal situação envolve, além da dimensão ética e do comprometimento de diferentes áreas do conhecimento, ações baseadas no domínio, difusão e produção de conhecimentos científicos relativos aos sistemas físicos e biológicos que compõem nosso planeta e à forma de utilização destes sistemas pelos seres humanos.

Nesse contexto a Química tem um papel importante. E ainda que se reconheça que seus conhecimentos e produtos deram enormes contribuições à melhoria na qualidade de nossas vidas, sobre ela também é imputada uma grande responsabilidade pelos danos ambientais ao planeta. É nesta espécie de "dialética da produção-destruição" que a Química é desafiada a rever muito de seus modelos teórico-práticos, com o fito de produzir alternativas científicas e tecnológicas que tenham em consideração a prevenção ambiental.

Especialmente as pesquisas denominadas de Química Verde (QV) parecem surgir como uma resposta a tais expectativas, e se inserem em um amplo, histórico e crescente movimento social, científico e tecnológico em defesa do meio biótico e abiótico. ${ }^{2}$ Como um novo campo de pesquisa e intervenção, a QV é conhecida por seus Doze Princípios $^{3}$ e fundamentalmente preconiza diversas linhas de atuação com vista a eliminar (ou ao menos minimizar) os impactos negativos dos produtos químicos e do seu fabrico e uso, por exemplo: o design de vias de síntese para a prevenção de resíduos, um dos grandes

*e-mail: bebeto@ced.ufsc.br problemas da indústria química; ${ }^{2}$ a economia atômica, para potencializar a desmaterialização; a eliminação de substâncias tóxicas, para a proteção proativa da saúde dos seres vivos; o uso de formas alternativas de energização das reações para baixar a intensidade energética, etc.

A QV vem contribuindo para o desenvolvimento científico e na inovação tecnológica associada à sustentabilidade. Todavia, ainda está pouco presente na formação acadêmica dos iniciantes em Química, nos cursos de graduação e mesmo na pós-graduação. ${ }^{4-6}$ Situação pouco desejável considerando os desafios que impõem os reconhecidos limites ambientais e dos "paradigmas" da diluição e risco, ${ }^{7,8}$ que vêm orientando, de forma preponderante, o desenvolvimento da Química nas questões relacionadas ao meio ambiente. Em seus mais de vinte anos, a QV tem se colocado como uma espécie de vertente aglutinadora e transversal das diferentes áreas da Química na direção da salvaguarda do ambiente, com inegáveis e qualificadas contribuições à proteção do meio biótico e abiótico. Hoje se conhece melhor seus campos de interesse, suas produções, aplicações e desafios futuros, embora, do ponto de vista filosófico, a questão ligada à ideia da Sustentabilidade Ambiental (SA) no desenvolvimento de práticas químicas mereça uma melhor definição, considerando que necessita ser ancorada aos limites físicos e materiais impostos pelo ambiente.

Recentemente Marques e Machado ${ }^{9}$ efetuaram uma análise de artigos em que a relação entre Sustentabilidade e QV foi mencionada, tomando como referência opiniões sobre o Desenvolvimento Sustentável (DS), publicadas especialmente na época da divulgação do Relatório Brundtland e da emersão da própria Química Verde ${ }^{10-14}$ e confrontando-as com autores que estavam envolvidos em práticas da QV (em sentido lato, incluindo a tecnologia química). Portanto, o foco de atenção do trabalho foi levantar a percepção do conceito de Desenvolvimento Sustentável no período em que a Química Verde começou a surgir (no início da década de noventa do século XX), caracterizando e discutindo a compreensão e utilização do conceito de DS pelos químicos. A análise apontou que quando são examinados artigos científicos internacionais mais recentes, a discussão sobre o DS parece ter progredido muito, mas a discussão sobre a relação entre 
seu conceito e a possibilidade do alcance da SA por via da QV não foi inteiramente considerada por muitos químicos verdes.

Para tanto, em sentido amplo, parece importante conhecer possíveis estilos de pensamento ${ }^{15}$ de pesquisadores da área da Química sobre o conceito de SA, tomadas a partir de suas experiências profissionais, produções acadêmicas e visões sobre ciência e meio ambiente. A presente pesquisa - cuja primeira etapa será aqui reportada e discutida - foi conduzida por meio de um questionário junto a pesquisadores do CNPq (Conselho Nacional de Desenvolvimento Científico e Tecnológico), Área Química, buscando compreender como estes entendem o conceito e situações envolvendo o alcance do DS, da Sustentabilidade em geral e da SA em aspectos particularmente relacionados à Química, aos postulados da Termodinâmica e a alguns dos princípios da Química Verde.

$\mathrm{O}$ artigo é estruturado partindo-se de discussões envolvendo a crise ambiental, o debate em torno do alcance da Sustentabilidade e o conceito de DS, em particular aquele formulado no Relatório Brundtland, ${ }^{16}$ o qual prega que "a humanidade deverá satisfazer as necessidades do presente sem comprometer a capacidade das gerações futuras para atender às próprias necessidades" (p. 09). Este Relatório, intitulado Our Common Future, foi elaborado em 1987 por uma Comissão constituída sob a égide das Nações Unidas (World Commission on Environmental and Development, WCED), presidida pela senhora G. O. Brundtland. Esta comissão procurou analisar a situação então vigente em que o desenvolvimento dos países avançados tanto impactava negativamente o ambiente, como era responsável por um profundo fosso entre esses países e aqueles menos desenvolvidos quanto ao nível de qualidade de vida atingido - e, portanto, avançar com propostas para promover a atenuação deste fosso, mediante novas formas de desenvolvimento que não deteriorassem mais o ambiente.

Assim, neste artigo, ancorados na tese de que a Sustentabilidade precisa ser vista à luz das componentes econômica, social e ambiental, concentramos a análise nesta última, destacando discussões sobre os determinantes termodinâmicos e ideias relacionadas aos "paradigmas" da diluição e do risco. Em seguida apresentam-se informações e os resultados da pesquisa — por meio de figuras — acompanhados de comentários analíticos sobre os dados resultantes. Finaliza-se o texto com a seção destinada às considerações finais, que inclui uma discussão geral sobre os resultados e as conclusões.

\section{Química e Sustentabilidade (Ambiental): limitações impostas pela Segunda Lei da Termodinâmica}

Atualmente é muito comum justificar e associar qualquer atividade humana - principalmente aquelas relacionadas ao desenvolvimento econômico ou que envolvam bens naturais — incorporando-lhes o termo Sustentável (ou ainda DS). No âmbito das atividades químicas, a situação não é diferente. E talvez o sucesso dessa nova terminologia se deva em parte à ambiguidade que a acompanha. ${ }^{17}$ Além disso, na Química, em especial, se faz necessária uma reflexão em torno da presumida SA em relação aos processos de transformações materiais e energéticas.

Partindo dessas considerações e da relevância de estudos sobre as causas e soluções à crise ambiental, discorre-se, nesta seção, sobre ideias envolvendo os termos DS, Sustentabilidade e SA, articulando-os à Termodinâmica, em especial aos limites impostos por esta (particularmente a Segunda Lei). Acrescentam-se ainda discussões sobre os denominados "paradigmas" da diluição e do risco e acerca das contribuições da QV à emersão de um novo "paradigma": o "paradigma ecológico".?

A crescente visibilidade e o aumento das discussões em torno da crise ambiental têm produzido maior entendimento sobre as componentes que envolvem o tema da Sustentabilidade, a qual se manifesta, fundamentalmente, em três diferentes dimensões: econômica, social e ambiental. Ao mesmo tempo, isto amplia sua complexidade ${ }^{18}$ e potencializa interpretações alternativas do conceito. ${ }^{19}$ Segundo Daly, ${ }^{20}$ a produção acadêmica no campo das ciências sociais e aplicadas também não deixa dúvidas sobre a importância do tema para todos nós, principalmente no campo da sociologia e da economia.

No campo econômico, a relação parece se colocar especialmente em torno do modelo de desenvolvimento, cujos processos e utilização de recursos energéticos e materiais envolvidos nas transformações requeridos para a sustentação das necessidades humanas — trazem inevitáveis consequências ao ambiente. Portanto, o contorno desses problemas parece ser parte de uma crise civilizatória, com foco principal na relação meio ambiente-sociedade.

Neste sentido, é necessário reconhecer que as atividades econômicas nutrem-se de matéria e energia, transformando matérias-prima de baixa entropia em produtos, acompanhados de resíduos de alta entropia, à custa de energia concentrada de baixa entropia que é dissipada como calor (energia de alta entropia), de acordo com a Segunda Lei da Termodinâmica. Para Georgescu-Roegen (apud Cechin) $)^{21}$ como "(o aumento da) entropia é uma lei irredutível da natureza” (p. 66), o meio ambiente estabelece limites inequívocos ao crescimento e ao atual modelo de progresso. Já Prigogine e Stengers, ${ }^{22}$ em seus estudos sobre a Termodinâmica da vida, discutem os sistemas abertos (e não isolados, como artificialmente estabelecido na Termodinâmica clássica) e fora do equilíbrio termodinâmico, sustentando que estes são formados e se mantêm devido às estruturas dissipativas que degradam energia recebida continuadamente e exibem ciclagem de materiais em seu entorno, a exemplo das plantas. Mas como nem todos os organismos vivos agem desse modo, a exemplo dos humanos — que não produzem o próprio alimento e que buscam energia consumindo a biomassa ou outros animais, em processos heterótrofos -, os resultados são um decréscimo da entropia no subsistema, com aumento no sistema maior de invólucro em que este se insere e a degradação irreversível de energia, embora com conservação da matéria.

Ambas as interpretações colocam a Termodinâmica no centro da análise sobre Sustentabilidade, indicando a imperiosa necessidade de considerá-la na análise crítica sobre "os fundamentos" e preceitos contidos na noção de DS formulado no Relatório Brundtland. ${ }^{16}$ Especialmente porque esta noção tenta conciliar as esferas "ecológica" e "social", sob a mediação da (autoimponente) esfera econômica, sustentada nas ideias desenvolvimentistas e de progresso, mesclada com alguns — ainda que importantes — preceitos socioambientais para lidar com as próprias anomalias do sistema, como a degradação acelerada do meio ambiente. ${ }^{23}$

No campo da sociologia, incluindo aqui as questões éticas e da política, Hull ${ }^{24}$ destaca que o conceito de DS é tomado como ponto de partida para uma nova visão de desenvolvimento social. Paehke, ${ }^{25}$ por sua vez, salienta sobre uma melhor definição do escopo da SA dentro daquilo que se denomina DS. Já Foladori ${ }^{26}$ ressalta que o conceito de Desenvolvimento Sustentável remete a uma "preocupação com o estado do meio ambiente" (p. 19), e que nos últimos vinte anos esta tem se tornado uma noção mais operativa, que orienta o desenvolvimento de metodologias para medir a Sustentabilidade. E, não obstante o grande avanço na matéria, tais metodologias "menosprezaram" as contradições sociais, reduzindo a problemática ambiental a uma mera, e por vezes exclusivamente, questão técnica.

Por outro lado, nos campos das ciências do ambiente e das ciências naturais, o destaque é para as discussões envolvendo, no geral, aspectos biológicos, e em particular, da ecologia, na qual aparecem fortemente as teses conservacionistas e preservacionistas dos bens naturais e as controvérsias entre Sustentabilidade vs. Conservação 
("saúde da terra"), muito difundidas no periódico Conservation Biology. ${ }^{27-29}$ No campo das ciências naturais, especialmente na área da Química, o debate em torno ao tema da Sustentabilidade parece ainda estar ganhando força, $2,30,31$ embora não seja desconhecido, pois a matéria e suas transformações são os objetos desta área de conhecimento. Neste sentido, como reconhecido por Kirchhoff "32 "a QV é uma ferramenta importante para alcançar a Sustentabilidade” (p. 237).

Assim, se de um lado persiste a ideia recorrente de que ao utilizar bens naturais para processos de transformação da matéria e para obtenção de energia, isso ajudará a alcançar um maior e mais duradouro equilíbrio (no sentido termodinâmico) — seja utilizando fontes renováveis, seja controlando a quantidade e a toxicidade dos resíduos dos processos - , do outro, tal aspiração parece conter e reconhecer uma crítica ao modelo de desenvolvimento econômico e social de nossa civilização industrial. Os estudos de Khan, ${ }^{12}$ ao discutir quatro aspectos correlacionados ao DS — um deles o conceitual —, relaciona o problema dos recursos não renováveis como limitações aos fatores de produção e à "estabilidade ambiental". Termo este que pode ser tomado como um "sinônimo" de SA, e, portanto, como qualificativo em relação ao seu alcance. Algo que não é trivial do ponto de vista da economia, da organização e da manutenção da vida em sociedade e para as pretensões da ciência, especialmente da Química, enquanto ciência da matéria e artífice de suas transformações, que reconhece que o escopo e os limites da Sustentabilidade (ambiental) afetam todos os campos da atividade humana. E isso, segundo Huesemann, ${ }^{33}$ nos faz lembrar que "todas as atividades industriais e econômicas têm inevitáveis consequências ambientais negativas" (p. 21), incluindo o fato de que na prática é impossível reciclar completamente todos os recursos não-renováveis. Aspecto que não deve fugir ao desenvolvimento da QV, dado que esta não é uma exceção. Além disso, como esta é concebida como uma componente transversal da Química, ${ }^{34}$ almeja-se realçar as conexões entre a QV e a Sustentabilidade, focadas na SA — um dos objetivos de nossa pesquisa —, aspectos que tornam o estudo do tema mais complexo.

Ao avaliar o problema da Sustentabilidade, Sciubba e Zullo ${ }^{35}$ utilizaram uma análise Termodinâmica — baseada no conceito de exergia - via a incorporação de energias renováveis às misturas de fontes de energia já usadas atualmente pela população humana (portanto, aumentando a complexidade do sistema relativamente à utilização de energia fóssil por si só) para calcular o limite da satisfação da taxa de consumo energético em distintos sistemas. Por este estudo, os autores afirmam que, para alguns sistemas e cenários, os estados sustentáveis são possíveis, mas estes são estados mais "estressados" que nos modelos simplificados. Por outro lado, estes cálculos excluem componentes importantes como, por exemplo, da saúde relacionada ao ser humano e a ética. Por conseguinte, a validade prática dos resultados não é clara, embora este trabalho ${ }^{35}$ mostre que o conceito de Sustentabilidade e o papel da energia ainda estão em aberto e que as suas relações necessitam ser melhor estudadas.

Thornton, ${ }^{8}$ ao discutir sobre a produção e proliferação em larga escala de materiais químicos sintéticos no ambiente, salienta sobre a necessidade de mudanças no campo da Química para um sistema que vise à proteção ambiental, pois o vigente, baseado no regime de controle da emissão de poluentes fundamentado no "paradigma" do risco, não é totalmente eficaz. Afirma que "o conceito da QV representa uma parte crítica dessa mudança, mas isto não é suficiente por si só” (p. 1231), e que esta somente contribuirá se fizer parte de uma nova política baseada no princípio da precaução, guiando assim para uma produção tecnologicamente sustentável e ecologicamente compatível. Porém, para o autor, este princípio ainda não dá a chave de como fazer para alcançá-lo. Neste sentido, salienta sobre a histórica predominância e também sobre os limites, com características de declínio e superação, que exerceram os "paradigmas" da diluição e do risco no desenvolvimento da própria Química, apontando para a emersão de um novo "paradigma", por ele denominado "paradigma ecológico" (p. 326). ${ }^{7}$ Para o autor, ${ }^{8}$ as bases desse novo "paradigma" assentam-se sobre quatro pilares (p. 1234): da descarga zero, da (tecnologia) produção limpa, da inversão do ônus da prova (reverse onus) e da eliminação de compostos e processos químicos nocivos (chemical sunsetting). Nessa linha de raciocínio sobre a crise de "paradigmas" do risco e da diluição, é necessário reconhecer que hoje já se colocou em crise a ideia da eficácia do efeito diluente, uma vez que conhecemos mais, por exemplo, sobre a deposição, dispersão e bioacumulação de diversos dos produtos tóxicos nos compartimentos ambientais. Os resultados de nossa "cultura dos tóxicos" 36 evidenciam nossa limitada habilidade de prever, manusear e diagnosticar os complexos impactos globais das descargas químicas, cujo aumento de produção e utilização de materiais no fabrico de produtos químicos tóxicos são cada vez mais frequentes. Isso porque tal aumento potencializou o grau de complexidade na diferenciação e no controle dos riscos ao ambiente, por conta da interação entre substâncias, extensão e fontes de exposição e uso, de modo que tampouco a ideia da gestão das consequências, uma das principais bases do "paradigma" do risco, nos permite segurança ambiental. ${ }^{7}$

Por tais aspectos, a QV tem se colocado promissoramente, seja como uma vertente que busca aglutinar transversalmente pesquisadores e profissionais do ensino das diferentes áreas, em especial as que tradicionalmente compõem a Química, seja em direção de um novo modo de desenvolver a Química, comprometido com a prevenção e salvaguarda do ambiente, por vezes denominada de "sustentabilidade" ambiental. Entendimentos que almejamos conhecer melhor.

\section{Nossa pesquisa: objetivos e metodologia}

A pesquisa buscou caracterizar as compreensões de investigadores ligados ao Conselho Nacional de Desenvolvimento Científico e Tecnológico (CNPq) - Área da Química, categoria 1 (A, B, C, D) relativas ao significado e ao alcance dos termos SA e DS, no âmbito da Química. Buscaram-se evidências de como esses pesquisadores avaliam que se possa fornecer sustentabilidade ao ambiente quando a fragilidade e os limites deste são por eles considerados.

O instrumento utilizado foi um questionário (material suplementar) contendo nove questões, com um espaço aberto, em cada questão, para comentários adicionais. Do levantamento junto à plataforma Lattes $^{37}$ do CNPq, no ano de 2011, resultaram 456 pesquisadores-bolsistas, os quais receberam via internet uma carta-convite para a participação na pesquisa, que incluía um link de acesso ao questionário para resposta on-line. Do total, 82 pesquisadores responderam o questionário, o que corresponde a uma taxa de retorno de $18 \%$. Alguns ainda acrescentaram comentários às suas respostas, mas apresentamos e discutimos aqui somente os dados quantitativos da pesquisa.

As nove questões foram compostas por um conjunto de pequenos textos expressando pontos de vistas sobre variados aspectos relativos aos temas da pesquisa, ${ }^{38}$ seguido de perguntas, cujas respostas fundamentalmente almejavam recolher o grau de concordância com o expresso [em oito questões as opções eram: muito de acordo (MdA), de acordo (dA), muito em desacordo (MeD), em desacordo (eD) e indiferente (In); na questão 05 eram: "muito, pouco, nenhuma, independente e não se relaciona"].

Para efeitos analíticos, estas questões serão aqui agrupadas, sinteticamente, em quatro blocos. $\mathrm{O}$ primeiro bloco diz respeito à definição conceitual de Desenvolvimento Sustentável apresentado no Relatório Brundtland, ${ }^{16}$ se a mesma seria suficiente, eficiente ou vaga e contraditória. Ainda nesse bloco inicia-se a "problematizar" sobre o alcance dessa definição conceitual (questão 2), também ligada a uma visão de SA. Para tanto, são apresentadas outras visões, cuja natureza 
advém de outras áreas ou campos do conhecimento, fazendo com que os pesquisadores se posicionem sobre eventuais incompletudes na definição de Brundtland. ${ }^{16}$ Já no segundo bloco (questões 3, 4A e 4B), apresentaram-se cenários, possíveis significados e implicações sobre o alcance e manutenção de um estado de equilíbrio, elemento considerado nodal para a definição de DS e da SA. Colocaram-se ainda questões que, ao se reconhecer a tese da existência de uma crise civilizatória devido à contradição entre um mundo com recursos finitos e um crescimento ilimitado da produção, buscavam um posicionamento dos pesquisadores sobre escolhas relacionadas a possíveis soluções (neste caso, ligadas ao uso sustentável e ao regime de utilização de recursos materiais), bem como às questões da tecnologia para permitir superar as limitações dos recursos ao crescimento. No terceiro bloco (questões $4 \mathrm{C}$ e 5), entrando em aspectos mais familiares à área da Química, a partir de afirmações relacionadas aos fenômenos químicos e ao princípio de conservação de matéria bem como ponderações sobre aspectos relacionados à degradação de energia, buscou-se a opinião dos investigados sobre o grau de relação causal existente nos processos de transformação química e os efeitos ao alcance da SA. Introduziram-se, assim, ainda que de forma indireta, elementos relacionados aos limites físicos impostos pela Segunda Lei da Termodinâmica. Nas perguntas finais, no quarto e último bloco do questionário (questões $6,7,8$ e 9), buscou-se apresentar e explorar situações cujas respostas pudessem favorecer a explicitação de visões sobre os "paradigmas" da diluição e do risco, relacionadas à presença e controle de poluentes ambientais (tóxicos) de origem antropogênica, sobre a existência de soluções (controle de risco) e sobre o reconhecimento de limites das mesmas (expressando a crise desses "paradigmas"). Finalizando o questionário, acenou-se para a ideia de um novo "paradigma ambiental", o "paradigma ecológico", 7 de modo a acentuar a necessidade da busca premente da sustentabilidade.

Por fim, salienta-se que este estudo será prosseguido com uma análise relacionando as produções científicas dos investigados com suas respostas ao questionário, buscando assim compreender os estilos de pensamento ${ }^{15}$ sobre DS e SA.

\section{RESULTADOS}

Pela análise da questão 1 (Figura 1), é possível identificar que dos 82 pesquisadores, 66 consideraram o conceito de DS expresso no Relatório Brundtland como suficiente (33 MdA e 33 dA, 80,5\%). Adicionalmente, se os consideramos em conjunto com os que avaliaram essa formulação como eficiente ( 59 pesquisadores escolheram as opções MdA (16) e dA (43), 72,0 \%), podemos interpretar que uma maioria significativa dos pesquisadores está satisfeita com esta definição.

Todavia, se tomarmos os 26 pesquisadores que consideram essa formulação conceitual vaga e contraditória (questão 1C), e cruzarmos com suas respostas anteriores (1A e 1B), percebe-se que 11 destes também a consideram suficiente e eficiente (estando dA ou MdA), dando indicativo de uma "dificuldade" destes pesquisadores em interpretar o conceito de DS ou uma compreensão contraditória acerca do mesmo. Algo que para outros 15 pesquisadores parece não ocorrer, pois por algum motivo estão convictos que a formulação conceitual é vaga e contraditória. De todo modo, isto deve ser analisado no conjunto geral das respostas.

Em seguida se ofereceu um segundo conjunto de questões com outras formulações envolvendo a noção de DS, na perspectiva da Sustentabilidade, por meio de visões conceituais sobre sua natureza econômica, sociológica, de planejamento, biológica, social e ética. Portanto, envolvendo outras áreas ou campos do conhecimento. Por meio do grau de concordância, discordância ou indiferença com tais

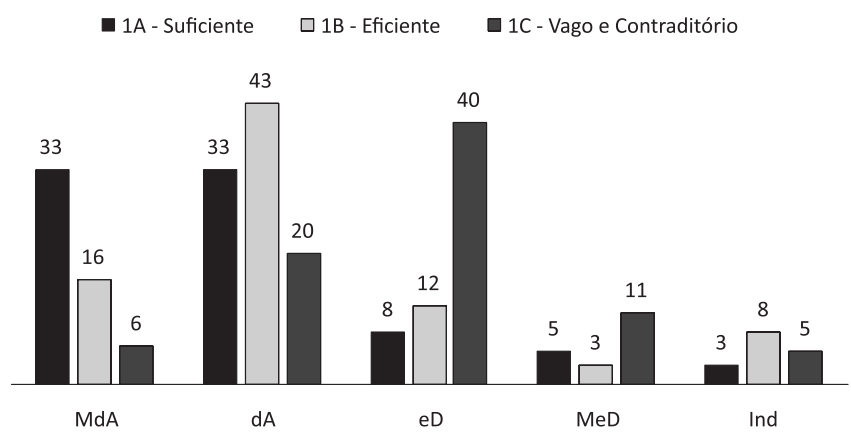

Figura 1. Graus de concordância com o conceito Brundtland de Desenvolvimento Sustentável - Questão 1 (A, B, C)

formulações buscou-se acompanhar a natureza das suas possíveis (in)satisfações conceituais com as escolhas já feitas nas respostas anteriores (1A e 1B). Ou seja, aqueles que concordaram (MdA e dA) com o conceito expresso no Relatório Brundtland provavelmente não o "complementariam", concordando com outras formulações. Ao contrário daqueles que tomaram o conceito de Brundtland como vago e contraditório, que provavelmente "incorporariam ou concordariam" com outras formulações. Todavia, isso não ocorreu completamente, como se pode perceber pela Figura 2, a qual representa um agrupamento das respostas a todos os itens da questão 2 .

$\square \mathrm{MdA} \square \mathrm{dA} \square \mathrm{MeD} \square \mathrm{eD} \square$ Ind

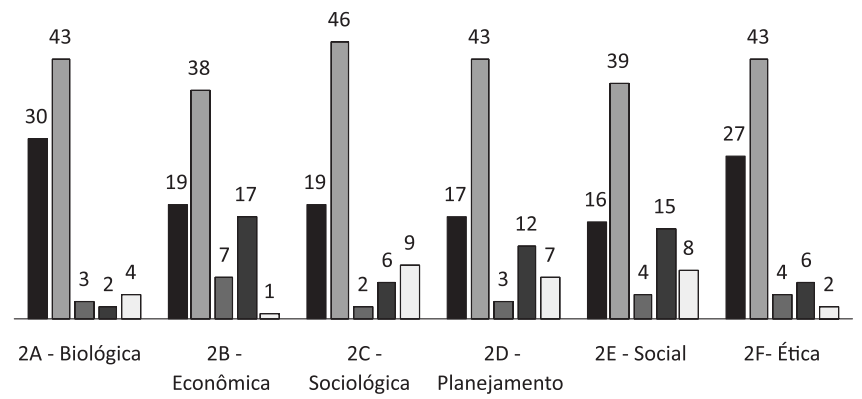

Figura 2. Graus de concordância com as opções das Questões 2 (A, B, C, $D, E, F)$ do Questionário

A primeira observação geral é que a maioria do grupo está "de acordo e muito de acordo" com todas essas outras formulações complementares à ideia de sustentabilidade contida no conceito de DS do Relatório Brundtland. As formulações de natureza sociológica (65), ética (70) e biológica (73) da sustentabilidade receberam maior concordância dos pesquisadores. Já as opções relativas à natureza de planejamento (60), econômica (57) e social (55) da sustentabilidade receberam uma concordância menor, mas ainda assim superior à metade dos pesquisadores. Talvez isto sinalize uma visão sobre o grau de influência dos agentes e das atividades econômicas no alcance e manutenção da sustentabilidade, bem como da justiça social que se pretende atingir com ela.

Em um segundo bloco de questões, cujas respostas estão representadas nas Figuras 3 e 4, foram apresentados alguns cenários, possíveis significados e algumas implicações sobre o alcance e manutenção de um estado de equilíbrio, elemento considerado chave para a definição sobre DS e SA. Inicialmente se apresentaram ideias relativas à existência de restrições (taxas) à extração de bens naturais versus à (taxa de) regeneração induzida ou natural dos mesmos. E, finalizando, apresentaram-se comentários sobre a utilização do meio ambiente como depósito de rejeitos (incluindo as falhas, como a existência da poluição). 
Cerca de $43 \%$ dos pesquisadores concordam, enquanto $55 \%$ não concordam, com a afirmação de que "Um estado de equilíbrio é um estado dinâmico em que as mudanças que ocorrem no meio ambiente cancelam umas às outras" (3A). E, avançando nesse foco sobre o estado de equilíbrio e seus condicionantes, a afirmação de que manter este "estado de equilíbrio entre os recursos naturais, espécies animais, vegetais e a poluição podem implicar no uso condicional dos recursos renováveis" (3B), trouxe à tona a ideia de limites (especialmente os limites físicos, o que permitiria relacioná-los com a Termodinâmica).

As respostas não surpreenderam: cerca de $84 \%$ responderam que estão de acordo com a existência de limites, reconhecendo o uso condicional de recursos renováveis. Mas a contradição aparente da maioria expressiva que considerou como satisfatória (suficiente e eficiente) a noção-conceito de DS e SA - no modo expresso pelo Relatório Brundtland - está no duplo reconhecimento de determinantes acerca da ideia de sustentabilidade. Isto é, aceitam a possibilidade do alcance do equilíbrio termodinâmico ao mesmo tempo em que reconhecem os limites físicos no uso dos recursos, ainda que renováveis. E embora essa aparente "contradição" indique implicitamente o reconhecimento dos postulados da Termodinâmica, tal domínio é imprescindível aos químicos e com quem trabalha na área da Química, como no caso dos bolsistas produtividade do CNPq.
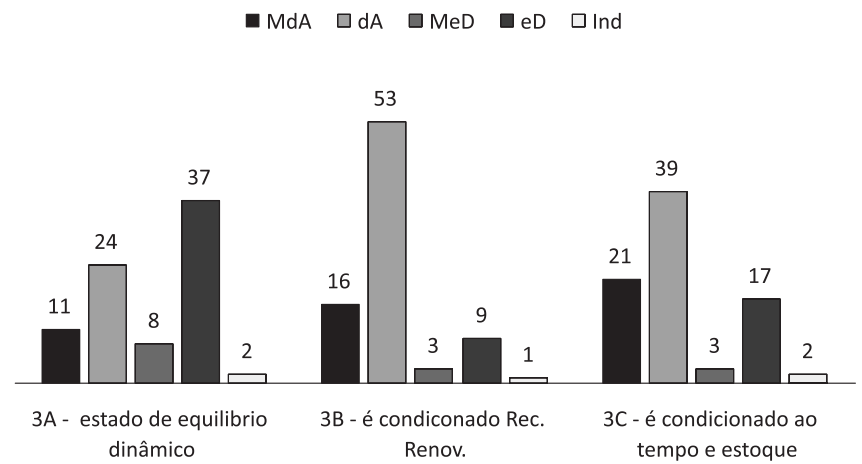

Figura 3. Graus de concordância sobre alcance e manutenção de um estado de equilíbrio à Sustentabilidade - Questão $3(A, B, C)$

Por fim, ainda no segundo bloco de questões, expôs-se sobre a existência de uma crise civilizatória, devido à contradição entre um mundo com recursos naturais finitos e um crescimento ilimitado da produção, através da qual se buscou oferecer escolhas aos pesquisadores para fazer emergir suas visões sobre possíveis soluções, considerando, por exemplo, o uso sustentável e o regime de utilização de materiais renováveis, assim como o desenvolvimento de tecnologias para permitir superar as limitações dos recursos naturais ao crescimento (questões 4A e 4B, da Figura 4).

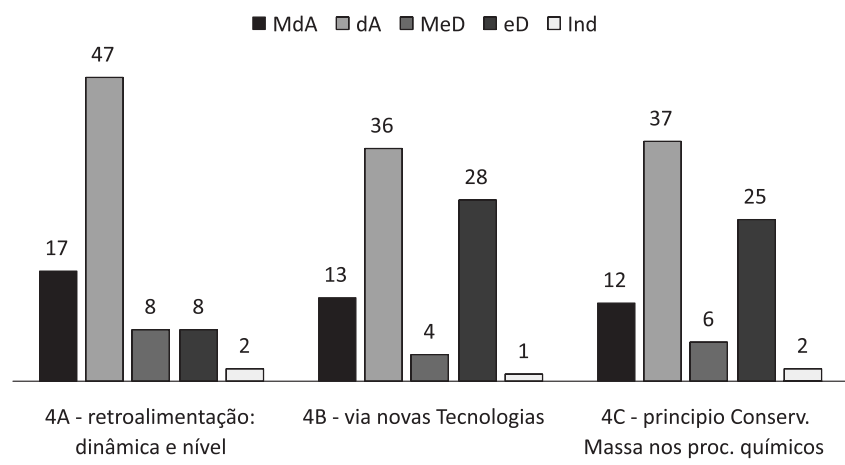

Figura 4. Graus de concordância sobre soluções à crise ambiental e os limites à Sustentabilidade - Questão 4 (A, B, C)
Na questão 4A os resultados apontam que a maioria dos pesquisadores $(64,78 \%)$ concorda que o uso e o regime de utilização de materiais renováveis têm uma limitação dinâmica e dependente da retroalimentação, enquanto que 32 mostraram-se em desacordo com a ideia de que o desenvolvimento de novas tecnologias permitiria a superação de tais limitações (questão 4B), de modo que uma pequena maioria (39, cerca de 44\%) parece crer em soluções tecnológicas. Um número similar de pesquisadores mostrou-se em desacordo com a ideia de que o princípio de conservação da matéria (Lavoisier) é importante para a sustentabilidade, em que as reações e processos químicos transformariam as causas ambientais em riqueza e bem-estar das pessoas (questão 4C). Já 49 pesquisadores expressaram concordância com este princípio. Por fim, observa-se que houve um padrão de resposta muito similar nos questionamentos 4B e 4C (Figura 4), o que pode ser um indício de que os pesquisadores interpretaram estas duas questões como sendo semelhantes, pois se relacionam à solução da crise ambiental por meio do desenvolvimento científico e tecnológico, ou seja, a maioria (64, cerca de $78 \%$ ) percebe que existem limites (4A), mas para um grupo menor (32), a ciência parece ter resposta para tudo.

Para efeitos de análise, o terceiro bloco de questões foi composto pelas questões $4 \mathrm{C}$ e 5 , dado que no conjunto estas questões apresentavam temáticas e situações mais relacionadas aos fenômenos químicos e aos princípios de conservação da matéria e da energia. $\mathrm{Na}$ questão 5 (A e B), abordando-se aspectos relacionados à degradação de energia, buscou-se interpretar as escolhas dos pesquisadores sobre o tipo de relação causal que entendem melhor expressar os efeitos dos processos de transformação química e o alcance da SA.
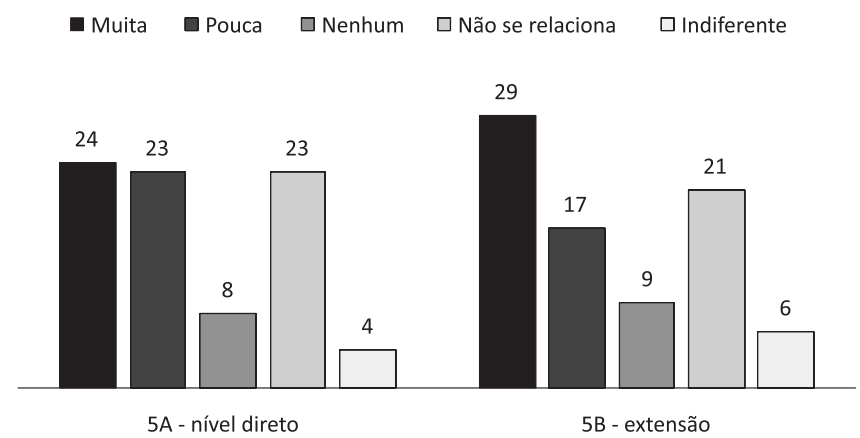

Figura 5. Relação entre efeitos da degradação de energia e limites à Sustentabilidade - Questão 5 (A, B)

Por meio da Figura 5 é possível perceber que 47 pesquisadores veem alguma (muito ou pouca) relação direta entre os efeitos da degradação da energia ao alcance e manutenção da SA. Resultado este que chama a atenção para os cerca de $37 \%$ que não veem relação alguma. Praticamente o mesmo percentual $(43,9 \%)$ foi observado na questão 5B, relativa ao grau de extensão com que a degradação da energia afeta a sustentabilidade, expressando visões que não consideram muito significativo tais efeitos-limite à sustentabilidade. Talvez isto reflita o fato de que estes pesquisadores da Química parecem não ver relação entre o problema da degradação da energia - ainda que em processos de transformação química — para o alcance da SA. Dito de outra forma, parecem se concentrar mais sobre aspectos das transformações da matéria, ainda que a (des) organização/transformação da matéria esteja associada a formas de degradação da energia.

No quarto e último bloco de questões (questões 6, 7, 8 e 9) buscou-se apresentar situações cujas respostas pudessem apresentar as visões sobre os "paradigmas" da diluição e do risco, relacionados à presença e controle de poluentes (tóxicos) de origem antropogênica em ambientes aquáticos, afirmando aspectos relacionados à 
existência de soluções ao problema da poluição (diluição e controle de risco) e reconhecimento de limites a estas. Por fim, acenou-se para um novo "paradigma ambiental", na busca incessante da sustentabilidade.

Na Figura 6 percebe-se que cerca de 85,4\% dos pesquisadores (70) consideram ser insuficiente a ideia de que a diluição de materiais tóxicos no ambiente resolveria o problema da poluição; o que de certa forma explica as respostas à pergunta subsequente, em que preponderantemente os pesquisadores $(59$, cerca de $72 \%$ ) consideram que há limites nessa "solução" ao problema da poluição. Contudo, esses dados revelam também certa contradição nas respostas, pois ao considerarem insuficiente a ideia de que a diluição de materiais tóxicos no ambiente resolveria o problema da poluição (questão 6A) esperava-se que o mesmo número de pesquisadores (70) estivesse em desacordo com a questão 6B, percebendo os limites do "paradigma" da diluição, algo que não ocorreu.

$\square$ MdA $\square$ dA $\square$ MeD $\square$ eD $\square$ Indiferente

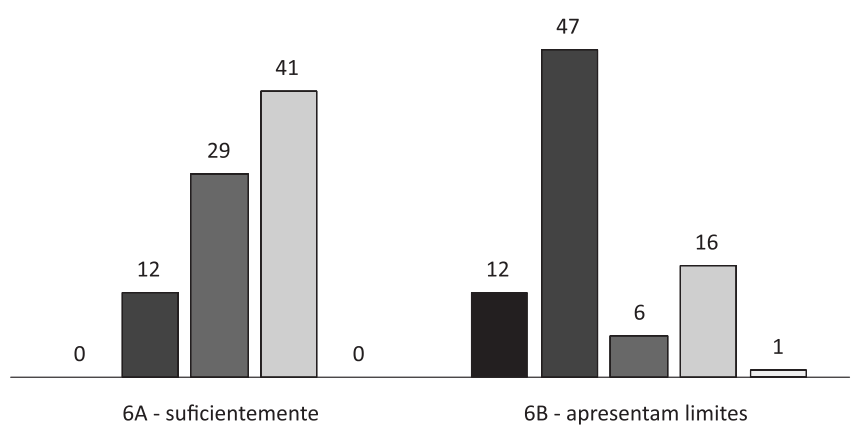

Figura 6. corpus d'água depuram poluentes ("paradigma” da diluição) Questão $6(A, B)$

Já nas Questões 7, 8 e 9, as respostas foram expressas em conjunto, pois as perguntas buscaram oferecer situações relativas à transição entre os "paradigmas" da diluição e do risco, apontando para a emersão de um novo "paradigma": o "paradigma ecológico".?

Como se pode observar pela Figura 7, a maioria (69 pesquisadores, cerca de $84 \%$ ) do grupo se expressou como estando de acordo e muito de acordo com a ideia base do "paradigma" do risco, por meio do tratamento diluente, como forma de reter/depurar os poluentes. Todavia, estiveram, em sua maioria, (muito) em desacordo com a eficácia de sistemas/tecnologias na eliminação completa dos poluentes. Por fim, se encontram divididos quanto ao grau de concordância com as bases que conformam um novo "paradigma" de condução à SA (questão 9A); bases estas expressas — por consequência dedutiva desse conjunto de questões precedentes - pela ideia do uso de recursos renováveis, de substâncias não tóxicas e na ecoeficiência da ciência e da tecnologia.

\section{CONSIDERAÇÕES FINAIS}

$\mathrm{Na}$ análise das respostas buscou-se, fundamentalmente, agrupar as tendências das escolhas, majoritárias ou não, do grupo enquanto coletivo de pesquisadores e não propriamente levantar contradições (coerência e incoerências) nas escolhas individuais. Portanto, as conclusões expressam tendências gerais com relação às visões do grupo pesquisado sobre as situações e conceitos expostos, especialmente sobre o tema da SA no âmbito das Ciências da Natureza/Química. Buscou-se cotejar em seguidos momentos do questionário sobre as limitações impostas pela Segunda Lei da Termodinâmica ao equilíbrio e à SA, dado que esta tem implicações no campo da Química, especialmente quando se almeja realçar as conexões entre a QV e o alcance da sustentabilidade, focadas na noção-conceito de SA.

Ao serem postos à reflexão depois de se manifestarem a favor da noção conceitual de DS, formulada pelo Relatório Brundtland, ${ }^{16}$ os pesquisados parecem evoluir para uma percepção sobre sua complexidade e incompletude. Avançando nas indagações, sobre o grau de dependência entre os recursos ambientais finitos e o problema da degradação da energia, bem como sobre os limites da tecnologia em relação à sustentabilidade, as manifestações foram uma boa indicação quanto ao emprego de fundamentos de base científica, ligados principalmente à Física e à Química, que devem ter orientado a análise e as escolhas dos pesquisadores em suas respostas.

Nas diferentes situações trabalhadas, principalmente aquelas ligadas aos limites do meio ambiente perante as ações antropogênicas, ao se explorar aspectos relacionados aos "paradigmas da diluição e do risco", as respostas não deixaram de evidenciar que os pesquisadores parecem reconhecer os limites desses dois "paradigmas" ao alcance da SA. Todavia, expressou-se certa divisão sobre as bases e a necessidade de um novo "paradigma" (o qual aqui denominamos "ambiental") na busca de práticas químicas para enfrentar esse desafio. Algo que poderá ser melhor compreendido investigando-se, por exemplo, a origem da formação dos estilos de pensamento ${ }^{15}$ de pesquisadores relativos às temáticas aqui exploradas no âmbito da Química.

Merece registro ainda o salientado na análise das respostas expressas na Figura 6, em que percebemos certa contradição nas respostas entre as questões 6A e 6B, mas tal "contradição" provavelmente reflete um problema na redação da questão $6 \mathrm{~B}$ (portanto, um limite de nosso instrumento de pesquisa) que dá a entender que se está tratando da concentração final do poluente e não da sua depuração.

Estes primeiros resultados da pesquisa indicaram as compreensões sobre sustentabilidade e o conceito de DS dos investigadores

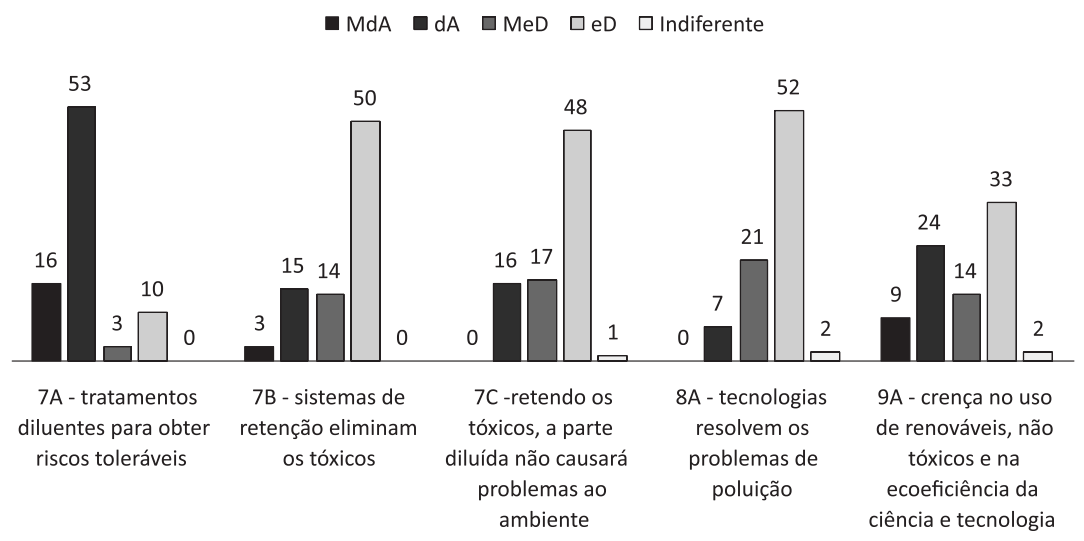

Figura 7. Relações entre os "paradigmas" de Risco, Diluição e Ecológico - Questões 7, 8 e 9 
e um reconhecimento sobre a exigência de se ter um modelo mais sustentável ao desenvolvimento com respeito aos limites impostos pelo ambiente, embora com pouco consenso sobre a natureza e a força destes limites. No tocante à SA e à sua relação tanto com os postulados da Termodinâmica quanto com os "paradigmas" da diluição e do risco, amplamente seguidos no controle ambiental, as escolhas das respostas às perguntas não são uniformes e atentas a tais limitações. Portanto, tais visões precisam ser "problematizadas", especialmente quando se consideram a complexidade dos sistemas ambientais e a busca por novas práticas químicas, como as desenvolvidas pela QV. Já sobre a emersão de um novo "paradigma ambiental", dirigido à Sustentabilidade, a análise das respostas sinaliza que isso demandará maior discussão na área da Química.

\section{AGRADECIMENTO}

Ao CNPq - Projeto Universal 47346/2010-2; à CAPES por meio do Acordo Internacional CAPES-FCT (Projeto 289/11), e aos pesquisadores que participaram da pesquisa.

\section{REFERÊNCIAS}

1. Porto, M. F. S.; Freitas, C. M.; Saúde, ambiente e sustentabilidade, FIOCRUZ: Rio de Janeiro, 2006.

2. Machado, A. A. S. C.; Quim. Nova 2011, 34, 535.

3. Anastas, P. T.; Williamson, T.C.; Green Chemistry - Frontiers in Benign Chemistry Syntheses, Oxford University Press: Oxford, 1998.

4. Marques, C. A.; Gonçalves, F. P.; Zampiron, E.; Coelho, J. C.; Mello, L. C.; Oliveira, P. R. S.; Lindemann, R. H.; Quim. Nova 2007, 30, 2043.

5. Marques, C. A.; Silva, R. M. G.; Gonçalves, F. P.; Fernandes, C. S.; Sangiogo, F. A.; Regiani, A. M.; Quim. Nova, 2012, no prelo.

6. Zuin, V. G.; Farias, C. R.; Freitas, D.; Revista Electrónica de Enseñanza de las Ciencias 2009, 8, 552.

7. Thornton, J.; Pandora's Poison: Chlorine, Health, and a New Environmental Strategy, MIT Press: Cambridge, 2000.

8. Thornton, J.; Pure Appl. Chem. 2001, 78, 1231.

9. Marques, C.A; Machado, A.A.S.C.; Found. Chem., 2013, no prelo.

10. Basiago, A. D.; Sustainable Development 1995, 3, 109.

11. Lélé, S. M.; World Development 1991, 19, 607.
12. Khan, M. A.; Sustainable Development 1995, 3, 63.

13. Goodland, R.; Annu. Ver. Ecol. Syst. 1995, 26, 1.

14. Taylor, L.; World Development 1996, 24, 215.

15. Fleck, L.; Gênese e desenvolvimento de um fato científico, Fabrefactum: Belo Horizonte, 2010.

16. WCED (World Commission on Environmental and Development): Our common future. Oxford University Press: Oxford, 1987.

17. Huesemann, M. H.; Environ. Prog. 2004, 23, 264.

18. Pawlowski, A.; Sustainable Development 2008, 16, 81.

19. Kate, R. W.; Paris, T. M.; Environment 2005, 47, 8.

20. Daly, H. E.; Steady-state Economics, $2^{\text {nd }}$ ed., Island Press: Washington, 1991.

21. Cechin, A.; A natureza como limite da economia: a contribuição de Nicholas Georgescu-Roegen, Ed. Senac/Edusp: São Paulo, 2010.

22. Prigogine, I.; Stengers, I.; Order Out of Chaos: Man's New Dialogue with Nature, Bantam: New York, 1984.

23. Montibeller-Filho, G.; O Mito do Desenvolvimento Sustentável. Meio ambiente e custos sociais no moderno sistema produtor de mercadorias, $3^{\mathrm{a}}$ ed., Ed. UFSC: Florianópolis, 2008.

24. Hull, Z.; Sustainable Development 2008, 16, 73.

25. Paehke, R.; Environmental Politics 2001, 10, 1.

26. Foladori, G.; Ambiente \& Sociedade 1999, Ano II, 5, 19.

27. Newton, J. L.; Freyfogle, E. T.; Conservation Biology 2005, 19, 23.

28. Ehrenfeld, D.; Conservation Biology 2005, 19, 33.

29. Paehke, R.; Conservation Biology 2005, 19, 36.

30. Winterton, N.; Clean Technol. Environ. Policy 2003, 5, 8.

31. Graedel, T. E. Em Handbook of Green Chemistry and Technology; Clark, J. H.; Macquarrie, D., eds,; Willey and Sons Ed. 2002, cap. 4.

32. Kirchhoff, M. M.; Resources, Conservations and Recycling, 2005, 44, 237.

33. Huesemann, M. H.; Clean Tech. Environ. Policy 2003, 5, 8.

34. Anastas, P. T.; Williamson, T. C.; Hjeresen, D.; Breen, J. J.; Env. Sci. Technol. 1999, 33, 116A.

35. Sciubba, E.; Zullo, F.; J. Ind. Ec. 2011, 15, 172.

36. Hofrichter, R.; Reclaiming the environmental debate: the politics of health in a toxic culture, ed. MIT Press: Cambridge, 2000.

37. Plataforma Lattes: http://lattes.cnpq.br.

38. Zylbersztajn, A.; Rev. Bras. Ensino Fís. 2003, 25, 1. 


\section{SUSTENTABILIDADE AMBIENTAL: UM ESTUDO COM PESQUISADORES QUÍMICOS NO BRASIL}

\section{Carlos Alberto Marques*}

Departamento de Metodologia de Ensino da Universidade Federal de Santa Catarina, CP 476, 88040-970 Florianópolis-SC, Brasil

Fábio Peres Gonçalves e Santiago Francisco Yunes

Departamento de Química da Universidade Federal de Santa Catarina, CP 476, 88040-970 Florianópolis-SC, Brasil

Adélio A. S. C. Machado

Departamento de Química, Faculdade de Ciências da Universidade do Porto, R. do Campo Alegre, 687, Porto 4169-007, Portugal

\section{Questionário de Pesquisa}

Neste instrumento de pesquisa existe um conjunto de pequenos textos ou afirmações expressando pontos de vista relativos ao Desenvolvimento Sustentável (DS) e à Sustentabilidade Ambiental (SA), e sua relação com a Química. Em cada uma dessas situações, solicitamos que expresse, na ordem sequencial das questões, seu grau de concordância, assinalando a categoria de sua escolha. Se desejar acrescente um comentário, justificando os motivos de sua escolha, o qual nos será extremamente útil.

\section{Considere a afirmação abaixo}

o desenvolvimento de uma civilização...deve satisfazer as necessidades da geração presente, sem comprometer a capacidade das gerações futuras para satisfazer suas próprias necessidades.

Há autores que consideram essa noção conforme as alternativas abaixo. E você, como a considera:

\section{A - Suficiente}

\begin{tabular}{|l|l|c|c|c|}
\hline $\begin{array}{c}\text { ( ) Muito } \\
\text { de Acordo }\end{array}$ & $\begin{array}{c}\text { ( ) De } \\
\text { Acordo }\end{array}$ & $\begin{array}{c}\text { ( ) Em } \\
\text { desacordo }\end{array}$ & $\begin{array}{c}\text { ( ) Muito } \\
\text { em Desa- } \\
\text { cordo }\end{array}$ & $\begin{array}{c}\text { ( ) Indife- } \\
\text { rente }\end{array}$ \\
\hline
\end{tabular}

\section{B - Eficiente}

\begin{tabular}{|c|c|c|c|c|}
\hline $\begin{array}{c}\text { ( ) Muito } \\
\text { de Acordo }\end{array}$ & $\begin{array}{c}\text { ( ) De } \\
\text { Acordo }\end{array}$ & $\begin{array}{c}\text { ( ) Em } \\
\text { desacordo }\end{array}$ & $\begin{array}{c}\text { ( ) Muito } \\
\text { em Desa- } \\
\text { cordo }\end{array}$ & $\begin{array}{c}\text { ( ) Indife- } \\
\text { rente }\end{array}$ \\
\hline
\end{tabular}

\section{C - Vaga e contraditória}

\begin{tabular}{|l|c|c|c|c|}
\hline $\begin{array}{c}\text { ( ) Muito } \\
\text { de Acordo }\end{array}$ & $\begin{array}{c}\text { ( ) De } \\
\text { Acordo }\end{array}$ & $\begin{array}{c}\text { ( ) Em } \\
\text { desacordo }\end{array}$ & $\begin{array}{c}\text { ( ) Muito } \\
\text { em Desa- } \\
\text { cordo }\end{array}$ & $\begin{array}{c}\text { ( ) Indife- } \\
\text { rente }\end{array}$ \\
\hline
\end{tabular}

\section{Acrescente um comentário se desejar:}

2. O Desenvolvimento Sustentável envolve um processo de mudança nas mais variadas dimensões, representando uma alentadora tentativa de reconciliar a busca do bem-estar presente com a segurança das condições de vida no futuro. Algo que expressaria uma visão sobre sustentabilidade, de modo que se poderia afirmar que esta visão é de natureza:
A - Biológica, com o termo "sustentabilidade" sendo associado à proteção da biodiversidade.

\begin{tabular}{|c|c|c|c|c|}
\hline $\begin{array}{c}\text { ( ) Muito } \\
\text { de Acordo }\end{array}$ & $\begin{array}{c}\text { ( ) De } \\
\text { Acordo }\end{array}$ & $\begin{array}{c}\text { ( ) Em } \\
\text { desacordo }\end{array}$ & $\begin{array}{c}\text { ( ) Muito } \\
\text { em Desa- } \\
\text { cordo }\end{array}$ & $\begin{array}{c}\text { ( ) Indife- } \\
\text { rente }\end{array}$ \\
\hline
\end{tabular}

B - Econômica, onde a "sustentabilidade" seria desenvolvida por aqueles que empregam os recursos naturais no fabrico de bens e promovem a atividade econômica.

\begin{tabular}{|l|c|c|c|c|}
\hline $\begin{array}{c}\text { ( ) Muito } \\
\text { de Acordo }\end{array}$ & $\begin{array}{c}\text { ( ) De } \\
\text { Acordo }\end{array}$ & $\begin{array}{c}\text { ( ) Em } \\
\text { desacordo }\end{array}$ & $\begin{array}{c}\text { ( ) Muito } \\
\text { em Desa- } \\
\text { cordo }\end{array}$ & $\begin{array}{c}\text { ( ) Indife- } \\
\text { rente }\end{array}$ \\
\hline
\end{tabular}

C - Sociológica, com a "sustentabilidade" envolvendo a defesa da justiça ambiental.

\begin{tabular}{|l|c|c|c|c|}
\hline $\begin{array}{c}\text { ( ) Muito } \\
\text { de Acordo }\end{array}$ & $\begin{array}{c}\text { ( ) De } \\
\text { Acordo }\end{array}$ & $\begin{array}{c}\text { ( ) Em } \\
\text { desacordo }\end{array}$ & $\begin{array}{c}\text { ( ) Muito } \\
\text { em Desa- } \\
\text { cordo }\end{array}$ & $\begin{array}{c}\text { ( ) Indife- } \\
\text { rente }\end{array}$ \\
\hline
\end{tabular}

D - Planejamento, com a "sustentabilidade" sendo associada ao processo de revitalização urbana.

\begin{tabular}{|c|c|c|c|c|}
\hline $\begin{array}{c}\text { ( ) Muito } \\
\text { de Acordo }\end{array}$ & $\begin{array}{c}\text { ( ) De } \\
\text { Acordo }\end{array}$ & $\begin{array}{c}\text { ( ) Em } \\
\text { desacordo }\end{array}$ & $\begin{array}{c}\text { ( ) Muito } \\
\text { em Desa- } \\
\text { cordo }\end{array}$ & $\begin{array}{c}\text { ( ) Indife- } \\
\text { rente }\end{array}$ \\
\hline
\end{tabular}

E - Social, onde a "sustentabilidade" tem um significado de natureza social, válida para a escala do tempo histórico.

\begin{tabular}{|l|c|c|c|c|}
\hline $\begin{array}{c}\text { ( ) Muito } \\
\text { de Acordo }\end{array}$ & $\begin{array}{c}\text { ( ) De } \\
\text { Acordo }\end{array}$ & $\begin{array}{c}\text { ( ) Em } \\
\text { desacordo }\end{array}$ & $\begin{array}{c}\text { ( ) Muito } \\
\text { em Desa- } \\
\text { cordo }\end{array}$ & $\begin{array}{c}\text { ( ) Indife- } \\
\text { rente }\end{array}$ \\
\hline
\end{tabular}

F - Ética ambiental, onde a "sustentabilidade" tem um significado alternativo ao de preservação, conservação ou uso sustentável de recursos naturais.

\begin{tabular}{|c|c|c|c|c|}
\hline $\begin{array}{c}\text { ( ) Muito } \\
\text { de Acordo }\end{array}$ & $\begin{array}{c}\text { ( ) De } \\
\text { Acordo }\end{array}$ & $\begin{array}{c}\text { ( ) Em } \\
\text { desacordo }\end{array}$ & $\begin{array}{c}\text { ( ) Muito } \\
\text { em Desa- } \\
\text { cordo }\end{array}$ & $\begin{array}{c}\text { ( ) Indife- } \\
\text { rente }\end{array}$ \\
\hline
\end{tabular}


3. Manter um Estado de Equilíbrio é uma das definições de Desenvolvimento Sustentável. Isto significa que:

A. Um estado de equilíbrio é um estado dinâmico em que as mudanças que ocorrem no meio ambiente cancelam umas às outras.

\begin{tabular}{|l|c|c|c|c|}
\hline $\begin{array}{c}\text { ( ) Muito } \\
\text { de Acordo }\end{array}$ & $\begin{array}{c}\text { ( ) De } \\
\text { Acordo }\end{array}$ & $\begin{array}{c}\text { ( ) Em } \\
\text { desacordo }\end{array}$ & $\begin{array}{c}\text { ( ) Muito } \\
\text { em Desa- } \\
\text { cordo }\end{array}$ & $\begin{array}{c}\text { ( ) Indife- } \\
\text { rente }\end{array}$ \\
\hline
\end{tabular}

B. Manter este "estado de equilíbrio" entre os recursos naturais, espécies animais, vegetais e a poluição pode implicar no uso condicional dos recursos renováveis.

\begin{tabular}{|l|c|c|c|c|}
\hline $\begin{array}{c}\text { ( ) Muito } \\
\text { de Acordo }\end{array}$ & $\begin{array}{c}\text { ( ) De } \\
\text { Acordo }\end{array}$ & $\begin{array}{c}\text { ( ) Em } \\
\text { desacordo }\end{array}$ & $\begin{array}{c}\text { ( ) Muito } \\
\text { em Desa- } \\
\text { cordo }\end{array}$ & $\begin{array}{c}\text { ( ) Indife- } \\
\text { rente }\end{array}$ \\
\hline
\end{tabular}

C. O uso condicional dos recursos renováveis deverá ser determinado para cada região específica e para um determinado tempo de duração de forma que seu consumo não ultrapasse a formação de novos estoques.

\begin{tabular}{|l|l|c|c|c|}
\hline $\begin{array}{l}\text { ( ) Muito } \\
\text { de Acordo }\end{array}$ & $\begin{array}{c}\text { ( ) De } \\
\text { Acordo }\end{array}$ & $\begin{array}{c}\text { ( ) Em } \\
\text { desacordo }\end{array}$ & $\begin{array}{c}\text { ( ) Muito } \\
\text { em Desa- } \\
\text { cordo }\end{array}$ & $\begin{array}{c}\text { ( ) Indife- } \\
\text { rente }\end{array}$ \\
\hline
\end{tabular}

\section{Acrescente um comentário se desejar:}

4. À primeira vista, o argumento de que existe uma contradição insuperável entre um mundo com recursos finitos e um crescimento ilimitado da produção é convincente, reforçando a idéia de que a sociedade humana se defronta, em sua evolução, com limites físicos. Segundo esta compreensão:

A. O uso sustentável e o regime de utilização de materiais renováveis (ex. biomassa) têm uma limitação dinâmica, que depende do nível da retroalimentação.

\begin{tabular}{|l|c|c|c|c|}
\hline $\begin{array}{c}\text { ( ) Muito } \\
\text { de Acordo }\end{array}$ & $\begin{array}{c}\text { ( ) De } \\
\text { Acordo }\end{array}$ & $\begin{array}{c}\text { ( ) Em } \\
\text { desacordo }\end{array}$ & $\begin{array}{c}\text { ( ) Muito } \\
\text { em Desa- } \\
\text { cordo }\end{array}$ & $\begin{array}{c}\text { ( ) Indife- } \\
\text { rente }\end{array}$ \\
\hline
\end{tabular}

B. O desenvolvimento da tecnologia permitirá superar as limitações dos recursos e assim garantir o crescimento da produção.

\begin{tabular}{|l|c|c|c|c|}
\hline $\begin{array}{c}\text { ( ) Muito } \\
\text { de Acordo }\end{array}$ & $\begin{array}{c}\text { ( ) De } \\
\text { Acordo }\end{array}$ & $\begin{array}{c}\text { ( ) Em } \\
\text { desacordo }\end{array}$ & $\begin{array}{c}\text { ( ) Muito } \\
\text { em Desa- } \\
\text { cordo }\end{array}$ & $\begin{array}{c}\text { ( ) Indife- } \\
\text { rente }\end{array}$ \\
\hline
\end{tabular}

C. O princípio de Lavoisier sobre a conservação da matéria é fundamental para a sustentabilidade, uma vez que propicia que se trabalhe para a eliminação de problemas ambientais por meio de reações e processos químicos, o que permitirá transformar as causas de tais problemas em riqueza e bem-estar as pessoas.

\begin{tabular}{|l|c|c|c|c|}
\hline $\begin{array}{c}\text { ( ) Muito } \\
\text { de Acordo }\end{array}$ & $\begin{array}{c}\text { ( ) De } \\
\text { Acordo }\end{array}$ & $\begin{array}{c}\text { ( ) Em } \\
\text { desacordo }\end{array}$ & $\begin{array}{c}\text { ( ) Muito } \\
\text { em Desa- } \\
\text { cordo }\end{array}$ & $\begin{array}{c}\text { ( ) Indife- } \\
\text { rente }\end{array}$ \\
\hline
\end{tabular}

5. Apesar do princípio da conservação da energia, os fenômenos químicos envolvem degradação de energia. Isso permite concluir que:

A. A relação entre Sustentabilidade Ambiental e degradação da Energia é direta:

\begin{tabular}{|l|l|l|l|l|}
\hline ( ) Muito & ( ) pouco & $\begin{array}{c}\text { ( ) nen- } \\
\text { huma }\end{array}$ & $\begin{array}{c}\text { ( ) inde- } \\
\text { pende }\end{array}$ & $\begin{array}{c}\text { ( ) não se } \\
\text { relaciona }\end{array}$ \\
\hline
\end{tabular}

B. Que a extensão dessa degradação que afeta a sustentabilidade ambiental é:

\begin{tabular}{|l|l|l|l|l|}
\hline ( ) Muito & ( ) pouco & ( ) nenhuma & $\begin{array}{l}\text { ( ) inde- } \\
\text { pende }\end{array}$ & $\begin{array}{l}(\text { ) não se } \\
\text { relaciona }\end{array}$ \\
\hline
\end{tabular}

\section{Acrescente um comentário se desejar:}

6. Convencionou-se que poluição ambiental é a presença ativa de materiais introduzidos pelo homem (antropogênicos) que deterioram o meio, particularmente os materiais tóxicos. Assim:

A. Quando estamos nos referindo à água, a capacidade de diluição em geral expressa o quanto um corpo d'água (tal como rio, lago ou oceano) consegue espalhar e diluir as descargas de materiais tóxicos dos esgotos que recebe. Assim, a própria dinâmica dispersante da natureza que foi contaminada permite que haja depuração suficiente do poluente.

\begin{tabular}{|c|c|c|c|c|}
\hline $\begin{array}{c}\text { ( ) Muito } \\
\text { de Acordo }\end{array}$ & $\begin{array}{c}\text { ( ) De } \\
\text { Acordo }\end{array}$ & $\begin{array}{c}\text { ( ) Em } \\
\text { desacordo }\end{array}$ & $\begin{array}{c}\text { ( ) Muito } \\
\text { em Desa- } \\
\text { cordo }\end{array}$ & $\begin{array}{c}\text { ( ) Indife- } \\
\text { rente }\end{array}$ \\
\hline
\end{tabular}

B. Mas cada poluente se comporta de um jeito e o mesmo rio ou lago poderá diluir mais ou menos a carga de um tóxico, conforme ele seja mais ou menos solúvel em água, sofra ou não transformação/biodegradação, e a movimentação das águas for mais ou menos intensa, etc, pelo que a carga de poluição pode se manter mais ou menos concentrada.

\begin{tabular}{|l|c|c|c|c|}
\hline $\begin{array}{l}\text { ( ) Muito } \\
\text { de Acordo }\end{array}$ & $\begin{array}{c}\text { ( ) De } \\
\text { Acordo }\end{array}$ & $\begin{array}{c}\text { ( ) Em } \\
\text { desacordo }\end{array}$ & $\begin{array}{c}\text { ( ) Muito } \\
\text { em Desa- } \\
\text { cordo }\end{array}$ & $\begin{array}{c}\text { ( ) Indife- } \\
\text { rente }\end{array}$ \\
\hline
\end{tabular}

\section{Acrescente um comentário se desejar:}

7. Porém, quanto maior a concentração de um produto tóxico nas águas, maior é o risco de efeitos nocivos ao meio ambiente. Deste modo, para diminuir o risco introduzem-se nos processos industriais tratamentos em fim-de-linha com vista a reter uma fração dos materiais tóxicos.

A. Esse processo permite reduzir a concentração na descarga de materiais tóxicos para o meio ambiente até níveis correspondentes aos riscos supostamente toleráveis.

\begin{tabular}{|l|c|c|c|c|}
\hline $\begin{array}{c}\text { ( ) Muito } \\
\text { de Acordo }\end{array}$ & $\begin{array}{c}\text { ( ) De } \\
\text { Acordo }\end{array}$ & $\begin{array}{c}\text { ( ) Em } \\
\text { desacordo }\end{array}$ & $\begin{array}{c}\text { ( ) Muito } \\
\text { em Desa- } \\
\text { cordo }\end{array}$ & $\begin{array}{c}\text { ( ) Indife- } \\
\text { rente }\end{array}$ \\
\hline
\end{tabular}


B. E o material tóxico retido em fim-de-linha não mais causará impactos negativos no ambiente.

\begin{tabular}{|l|l|c|c|c|}
\hline $\begin{array}{c}\text { ( ) Muito } \\
\text { de Acordo }\end{array}$ & $\begin{array}{c}\text { ( ) De } \\
\text { Acordo }\end{array}$ & $\begin{array}{c}\text { ( ) Em } \\
\text { desacordo }\end{array}$ & $\begin{array}{c}\text { ( ) Muito } \\
\text { em Desa- } \\
\text { cordo }\end{array}$ & $\begin{array}{c}\text { ( ) Indife- } \\
\text { rente }\end{array}$ \\
\hline
\end{tabular}

C. Como houve uma retenção do material tóxico no fim-de-linha, ainda que exista uma toxicidade intrínseca do material a ser descarregado, devido à diluição da descarga não haverá problemas ao ambiente.

\begin{tabular}{|c|c|c|c|c|}
\hline $\begin{array}{c}\text { ( ) Muito } \\
\text { de Acordo }\end{array}$ & $\begin{array}{c}\text { ( ) De } \\
\text { Acordo }\end{array}$ & $\begin{array}{c}\text { ( ) Em } \\
\text { desacordo }\end{array}$ & $\begin{array}{c}\text { ( ) Muito } \\
\text { em Desa- } \\
\text { cordo }\end{array}$ & $\begin{array}{c}\text { ( ) Indife- } \\
\text { rente }\end{array}$ \\
\hline
\end{tabular}

Acrescente um comentário se deseja:
8. Evidentemente, as soluções encontradas ao problema da poluição, desde que aplicadas, já são totalmente suficientes para resolver essa situação de descarga de materiais tóxicos no meio ambiente.

\begin{tabular}{|l|c|c|c|c|}
\hline $\begin{array}{l}\text { ( ) Muito } \\
\text { de Acordo }\end{array}$ & $\begin{array}{c}\text { ( ) De } \\
\text { Acordo }\end{array}$ & $\begin{array}{c}\text { ( ) Em } \\
\text { desacordo }\end{array}$ & $\begin{array}{c}\text { ( ) Muito } \\
\text { em Desa- } \\
\text { cordo }\end{array}$ & $\begin{array}{c}\text { ( ) Indife- } \\
\text { rente }\end{array}$ \\
\hline
\end{tabular}

\section{Acrescente um comentário se deseja:}

9. Evidentemente, as soluções encontradas ao problema da poluição seriam totalmente dispensáveis numa situação onde não houvesse materiais tóxicos para descarga no meio ambiente.

\begin{tabular}{|l|c|c|c|c|}
\hline $\begin{array}{l}\text { ( ) Muito } \\
\text { de Acordo }\end{array}$ & $\begin{array}{c}\text { ( ) De } \\
\text { Acordo }\end{array}$ & $\begin{array}{c}\text { ( ) Em } \\
\text { desacordo }\end{array}$ & $\begin{array}{c}\text { ( ) Muito } \\
\text { em Desa- } \\
\text { cordo }\end{array}$ & $\begin{array}{c}\text { ( ) Indife- } \\
\text { rente }\end{array}$ \\
\hline
\end{tabular}

Acrescente um comentário se desejar: 